\title{
Energy Consumption from Conventional Gasoline Sedans in Beijing Based on the LEAP Model ${ }^{*}$
}

\author{
H.W. ZHENG, Y.Y. ZHANG \\ Academy of Chinese Energy Strategy, China University of Petroleum, Beijing, PR China
}

\begin{abstract}
To improve the urban air quality, Beijing adopted the most stringent vehicle control policies and strategies, including limitations on vehicle growth, the scrappage of older vehicles, and tail number limit line measure. This paper analyzes energy consumption of conventional gasoline sedans in Beijing until 2020 by applying LEAP model, considering the influence of vehicle age on fuel consumption rate, vehicle use intensity and vehicle survival rate. Our results show that conventional gasoline sedans stock in Beijing will reach 3.09 million and energy consumption will reach 3.61 million tons of oil equivalent by 2020 in business as usual scenario, increased by $7.8 \%$ and $8.6 \%$ compared to 2011 level, respectively. While in fuel consumption rate improved scenario and tail number limit line scenario, energy consumption will decrease compared to 2011 level. Sensitivity analysis is conducted to explore influence degree of vehicle use intensity and fuel consumption rate under the same change rate.
\end{abstract}

KEYWORD: LEAP model; Conventional gasoline sedans; Energy consumption

\section{INTRODUCTION}

Private car stock in China reached 105.02 million by 2013, including 4.25 million private cars in Beijing, accounting for about $4 \%$. Sedan is main part of private car stock. In 2013, there were 3.11 million sedans in Beijing, accounting for about $73 \%$ of private cars. Transportation field consumes large amount of energy each year. In 2011, transportation, storage, posts and telecommunications became the biggest gasoline consumption field in Beijing. So the future development, energy consumption and environmental emission of Beijing sedans become the focus of more and more researches. Chen et al. (2007) [1] analyzed the correlation between GDP per capita and car ownership per 1000 people in Beijing, forecasting that after the rapid development, private car stock will slow down the growth and gradually reach saturation. Yang et al. (2012) [9] analyzed private car stock, age distribution and scrappage in Beijing. Zhu (2004) [11] forecast development trend and energy demand of private cars in Beijing using Gompertz function, and discussed the effect of travel restrictions policy and fuel economy standards improvement on energy consumption. $\mathrm{Xu}$ et al. $(2013)^{[7]}$ forecast stock and energy consumption change of private cars in Beijing under increased cost scenario based on system dynamics model.

Many factors influence vehicle stock and energy consumption, and vehicle age is an important one among them. Researches mentioned above did not take vehicle age into consideration when predicting energy consumption. While in reality, fuel consumption rate (usually measured in liters of fuel per $100 \mathrm{~km}, \mathrm{FCR}$ ) and vehicle use intensity (kilometers travelled per vehicle per year or VKT) change as vehicle age grows. So energy consumption forecast will be affected. This article considers the influence of vehicle age, reflecting reality better. By designing different scenarios according to government policies, it discussed the influence of tail number limit line measure and fuel consumption rate on energy consumption.

\section{METHODOLOGY}

\subsection{LEAP model}

Long-range Energy Alternatives Planning System (LEAP) was developed by Stockholm Environment Institute (SEI) and Tellus Research Institute. It can be used for long-term energy environment planning, prediction of energy supply and consumption and 
pollutant emission of a country or city under different driving factors (Yu et al., 2013)[10]. This paper uses LEAP model to predict energy consumption of sedans in Beijing under different scenarios. The object is conventional gasoline sedans in Beijing. Set 2011 as base year and 2020 as end year. Energy consumption is calculated through Eq. (1):

$$
E C_{i}=\sum_{j=0}^{j=18}\left(F C R_{i j} \times V K T_{i j} \times V S_{i} \times R_{i j}\right)
$$

where $E C_{i}=$ energy consumption in year $i ; F C R_{i j}=$ fuel consumption rate of $j$ year old sedan in year $i$; $V K T_{i j}=$ kilometers travelled per vehicle per year of $j$ year old sedan in year $i ; V S_{i}=$ sedan stock in year $i$; $R_{i j}=$ proportion of sedan of $j$ year old in year $i ; i=$ year, from 2011 to $2020 ; j=$ age, from 0 to 18 .

Sedan stock is calculated through Eq. (2):

$$
\begin{aligned}
& V S_{i}=\sum_{k=2012}^{i}\left(\text { Sales }_{i k} \times \text { Sur }_{i-k}\right)+\sum_{j=1}^{18}\left(\text { VS }_{2011} \times R_{2011, j}\right. \\
& \left.\times \text { Sur }_{j+1-2001}\right)
\end{aligned}
$$

where Sales $_{k}=$ new purchase of sedans in year $k$; $\operatorname{Sur}_{j-k}=$ survival rate in year $i$ of sedan sold in year $k$; $\operatorname{Sur}_{j+i-2011}=$ survival rate in year $i$ of $j$ year old sedan in 2011; $k=$ year, from 2011 to 2020.

\subsection{Vehicle stock, stock structure and sales}

Figure 1 shows sedan stock and new vehicle sales from 2001 to 2013 in Beijing (Beijing Statistics Yearbook, 2002-2014). By 2011, sedan stock and sales were 2.86 million and 0.262 million in Beijing, respectively. Sales kept growing until 2011. In January 2011, Beijing began allocating vehicle license plates via a publicly held lottery. There were 20 thousand vehicle license plates every month, and numbers for personal account for $88 \%$. Each winner was permit to buy only one car. After 2011, sales of cars were under control. Yang et al. (2003) [8] forecast private passenger car sales in Beijing would reach 350 thousand under lottery scenario in 2020. Sales are approximately equal to the sum of vehicle license plates for individuals and cars scrapped in the last year, so there are about 140 thousand cars among 350 thousand which are scraped in 2019. But individuals whose vehicle is scraped can buy new vehicles without winning lottery.

By the end of 2014, new license plates are compressed to 150 thousand every year, and numbers for electric vehicles will gradually accounting for $40 \%$ by 2017. Assuming that this ratio will keep until 2020, numbers for traditional cars will be about 80 thousand every year. Adding to sales from scrappage, total sales of cars will reach 220 thousand.
The new regulations on motor vehicle mandatory scrapping standards in 2013 pointed out that sedans would not be limited to scrapped years, but would be scraped when total travelled kilometers reach 600 thousand kilometers. When cars reached 18 year old, survival rate is essentially zero (Yang et al. 2003) [8]. In this study, sedan lifetime is set to be 18 years, and survival rate of new generation declines as age grows. Table 1 shows the changes (Ou et al. 2010) [5].

China is lack of statistical data on the age distribution of the vehicle. Lin et al. (2009) [3] investigated vehicle mileage and vehicle age distribution of the mutual ground and above cities, and get the national statistics of vehicle age distribution of different vehicle types in 2007. Yang et al. (2003) [8] proposed a survival probabilitybased dynamic model, by which annual vehicle age distribution in Beijing in 2010 could be derived from total number of registered vehicles and total number of newly registered vehicles, and the age distribution of cars in 2010 is shown in Figure 2. It is more suitable to use result of Yang et al. when predict energy consumption in Beijing.

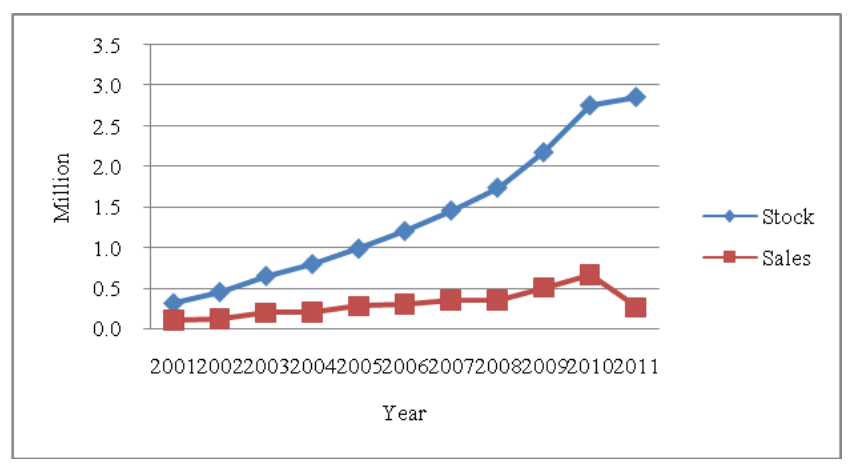

Figure 1. Sedan stock and sales from 2001 to 2013 in Beijing

Table 1. Survival rates of different ages.

\begin{tabular}{|c|c|c|c|c|c|c|}
\hline Age & 1 & 2 & 3 & 4 & 5 & 6 \\
\hline $\mathrm{R}(\%)$ & 100 & 100 & 100 & 100 & 100 & 100 \\
\hline Age & 7 & 8 & 9 & 10 & 11 & 12 \\
\hline R $(\%)$ & 100 & 96 & 82 & 78 & 64 & 59 \\
\hline Age & 13 & 14 & 15 & 16 & 17 & 18 \\
\hline R $(\%)$ & 43 & 36 & 26 & 10 & 3 & 0 \\
\hline
\end{tabular}

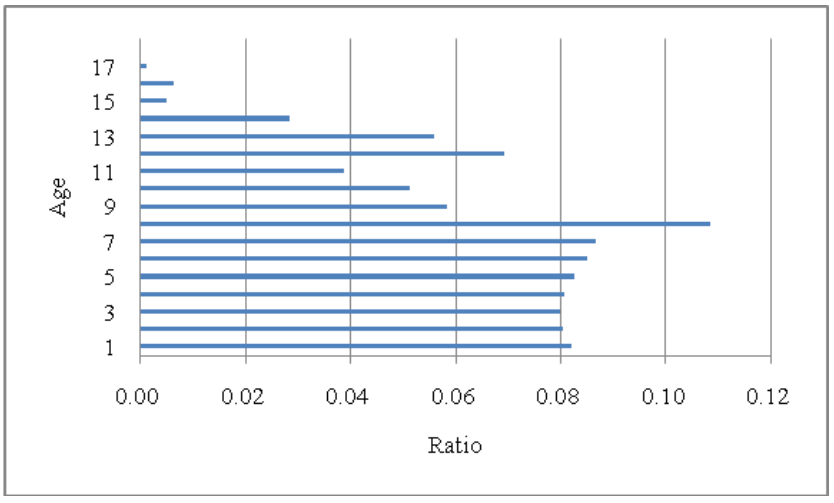

Figure 2. Age distribution of cars in Beijing in 2010. 


\subsection{FCR and VKT}

The average fuel consumption rate of China passenger vehicle in 2011 was $7.5 \mathrm{~L} / 100 \mathrm{~km}$, meeting the second stage standard of "Passenger Car Fuel Consumption Limit" in China. But it did not reach the target value of the third stage (Ma et al. 2012)[4].

Fuel consumption rate (FCR) ranges from 7.0 $\mathrm{L} / 100 \mathrm{~km}$ to $9.7 \mathrm{~L} / 100 \mathrm{~km}$ for sedans in our country. In this article, FCR of new sedan is set to be 7.5 $\mathrm{L} / 100 \mathrm{~km}$, and increase as age grows. Shigemi et al. (2013)[6] put forward FCR of different ages. By processing data in Shigemi's study, the ratio of FCR of different ages to 0 year old is shown in Figure 3, and it is used in this article because China lacks data of FCR changes as vehicle age grows.

VKT also declines as vehicle age grows. Figure 3 shows the ratio of VKT of different ages to 0 year old (Huo et al. 2012)[2]. VKT of sedan in Beijing in 2011 was about 15,000km (Zhu. 2003) [11], combined with VKT ratio, VKT of new sedan in Beijing is set to be $24,000 \mathrm{~km}$.

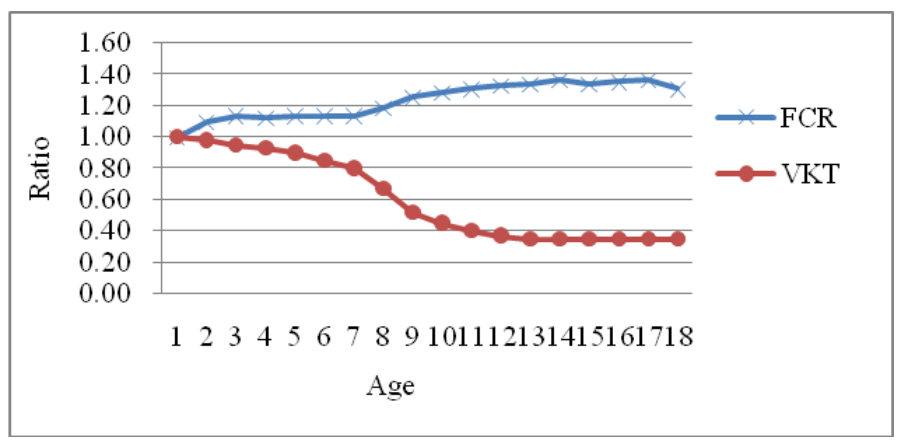

Figure 3. Ratio of FCR and VKT.

\subsection{Business as Usual (BAU) Scenario}

In BAU scenario, current policy is considered to remain unchanged until 2020. New policy will not be proposed. Suppose vehicle technology will not make breakthrough, and FCR as well as VKT keep current level. Lottery policy and tail number limit line measure will be the same as in 2014 .

\subsection{Fuel consumption rate improved (FRI) scenario}

In FRI scenario, FCR will reach $6.9 \mathrm{~L} / 100 \mathrm{~km}$ and 5 $\mathrm{L} / 100 \mathrm{~km}$ by 2015 and 2020, respectively according to "Energy Saving and New Energy Industry development Plan from 2012 to 2020". Other factors will remain the same as in BAU scenario. In FRI scenario, in order to analyze the effect of FCR on total energy consumption, sensitivity analysis is applied in this article when FCR increased by $10 \%$, $20 \%$ and decreased by $10 \%, 20 \%$.

\subsection{Tail number limit line measures (TNL) scenario}

VKT declines as vehicle stock increase. "The 12th five-year period of Beijing traffic development Plan" proposed single and double tail number limit line in key traffic jam. This policy will also lead decrease of VKT. Suppose VKT of sedans in Beijing decrease to $18,000 \mathrm{~km}$, while other factors remain the same as in BAU scenario. Sensitivity analysis is applied to analyze the effect of VKT on energy consumption.

\subsection{Combined scenario}

In combined scenario, both FCR and VKT are considered. It is the combination of FRI scenario and TNL scenario.

\section{RESULT}

\subsection{Sedan stock}

Growth of sedan stock in Beijing will be slowed down from 2011 to 2020 . Total sedans will be about 3.01 million and 3.09 million by 2015 and 2020, increased by $5.3 \%$ and $7.8 \%$ compared to 2011 level, respectively. The annual growth rate will be about $0.756 \%$. Sedan stock remains the same in different scenarios. Growth gradually becomes slow compared to the trend between 2001 and 2011. Lottery policy has positive effects on controlling sedan stock.

\subsection{Energy consumption under different scenarios}

In BAU scenario, total energy consumption grows gradually from 2011 to 2018 and decrease after 2018. In 2020, energy consumption of sedans in Beijing is up to 3.61 million tons of oil equivalent, increasing by $8.6 \%$ compared to 2011. Energy consumption in FRI scenario, TNL scenario and combined scenario in 2020 is all less than BAU scenario as shown in Figure 5. Improved FCR will reduce energy consumption by $12.8 \%$ in 2020 compared to 2011 level in FRI scenario. Decrease of VKT will also reduce energy consumption in 2020 by $11.8 \%$ in TNL scenario. In combined scenario, effect of energy saving is the most obvious. Energy consumption will reach 2.81 million tons of oil equivalent, decreasing by $22.2 \%$ compared to 2011 level. Both improved FCR and VKT reduction play important roles in energy saving.

\subsection{Result of sensitivity analysis}

Sensitivity analysis results show that energy consumption has positive correlation with both FCR and VKT. But when FCR and VKT vary by the same proportion, VKT has a greater impact on energy consumption. Table 2 shows sensitivity analysis results. 


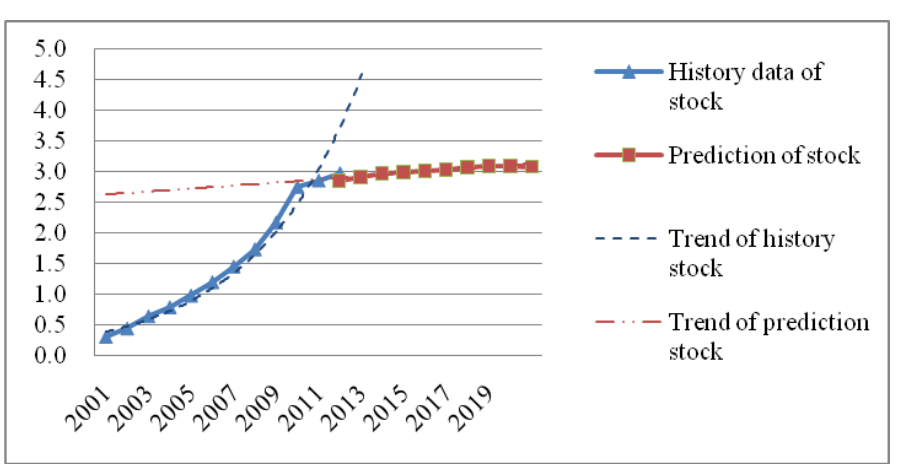

Figure 4. History data and prediction of sedan stock in Beijing.

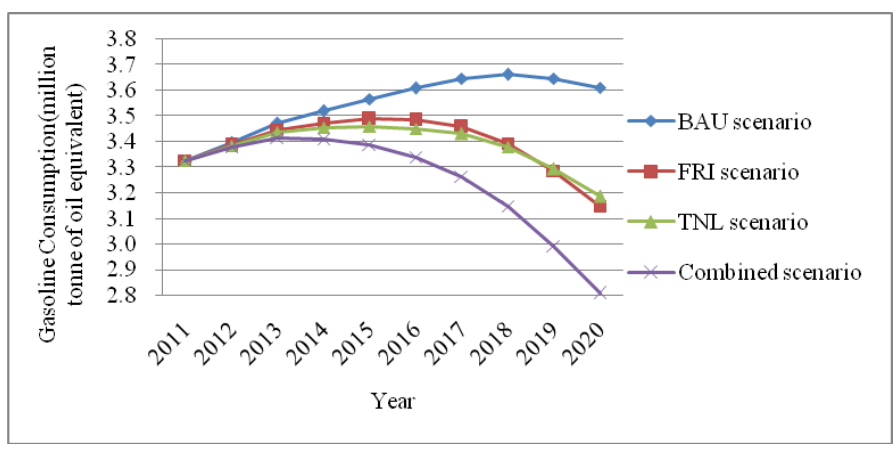

Figure 5. Energy consumption of sedans in Beijing in different scenarios.

Table 2. Energy consumption and change rate in 2020 in sensitivity analysis.

\begin{tabular}{|c|c|c|c|}
\hline Variable & $\begin{array}{c}\text { Change } \\
\text { rate }\end{array}$ & $\begin{array}{c}\text { Energy } \\
\text { consumption* }\end{array}$ & $\begin{array}{c}\text { Energy consumption } \\
\text { change rate }\end{array}$ \\
\hline \multirow{4}{*}{ FCR } & $+20 \%$ & 3.28 & $+4.34 \%$ \\
\cline { 2 - 4 } & $+10 \%$ & 3.22 & $+2.17 \%$ \\
\cline { 2 - 4 } & 0 & 3.15 & 0 \\
\cline { 2 - 4 } & $-10 \%$ & 3.08 & $-2.17 \%$ \\
\cline { 2 - 4 } & $-20 \%$ & 3.01 & $-4.34 \%$ \\
\hline \multirow{4}{*}{ VKT } & $+20 \%$ & 3.44 & $+8.04 \%$ \\
\cline { 2 - 4 } & $+10 \%$ & 3.31 & $+4.02 \%$ \\
\cline { 2 - 4 } & 0 & 3.19 & 0 \\
\cline { 2 - 4 } & $-10 \%$ & 3.06 & $-4.02 \%$ \\
\cline { 2 - 4 } & $-20 \%$ & 2.93 & $-8.04 \%$ \\
\hline
\end{tabular}

* Unit of energy consumption is million tons of oil equivalent.

\section{CONCLUSION}

Beijing's private car stock in 2001 and 2010 has maintained rapid growth. Lottery policy effectively controls the development trend after 2011, also lowers the growth of energy consumption. If combined with improved FCR and restrictions on tail number limit line measure, energy consumption will be controlled effectively by 2020. Compared with FCR, VKT have a greater impact on energy consumption when same change proportion occurs. To achieve the goal of reducing energy consumption in Beijing, accelerating the implementation of vehicle fuel consumption rate standards and tail number limit line measure, reducing vehicle travelling frequency will be effective methods.

\section{REFERENCES}

[1] Chen, S.H. \& Liu, X.M. 2007. The Developing Trend of Cars in Beijing Based on the Logistic Increase Model. Journal of Highway and Transportation Research and Development 24(9): 132-135 (in Chinese).

[2] Huo, H., Zhang, Q., He, K., et al. 2012. Vehicle-use intensity in China: Current status and future trend. Energy Policy 43: 6-16.

[3] Lin X.L., Tang D.G., Ding Y. et al. 2010. Study on the Distribution of Vehicle Mileage Traveled in China. Research of Environmental Sciences 22(3): 377-3816(in Chinese).

[4] Ma D., An, F., Kang, L.P., et al. 2012. Corporate average fuel consumption (CAFC) and its limit standard of passenger vehicle in China. Automotive Safety and Energy 3(4): 364-370(in Chinese).

[5] Ou X.M., Zhang X.L., Chang S.Y. 2010. Scenario analysis on alternative fuel/vehicle for China's future road transport: Life-cycle energy demand and GHG emissions. Energy Policy 38: 3943-3956.

[6] Shigemi K., Klaus H., Keisuke N., et al. 2013. Better cars or older cars? Assessing $\mathrm{CO} 2$ emission reduction potential of passenger vehicle replacement programs. Global Environmental Change 23: 1807-1818.

[7] Xu, L.P., Tang, X.R., Tong, H.F. 2013. Analysis and Prediction of Energy Demand Change of Cars in Beijing. Academic frontier sciences in 2013 -- the Chinese dream: education reform and people's quality promotion (part two ): 534-541(in Chinese).

[8] Yang, F., Yu, L., Song, G. 2003. Modeling Dynamic Vehicle Age Distribution in Beijing. Institute of Electrical \& Electronics Engineers Proceeding of the 6th IEEE International Conference on Intelligent Transportation System, Shanghai, China, 12-15 October 2003:78038125.

[9] Yang, Y., He, D.F., Tong, H.F. 2012. A Simulation Model of Private Cars in Beijing for Policy Simulation. China Soft Science (6): 78-89(in Chinese).

[10] Yu, H., Yang, R.G., Zhang, Y.J. 2013. Study on the Energy Demand and Environmental Emissions of Urban Transport, A Case Study of Beijing. Journal of Beijing Institute of Technology (Social Sciences Edition) 15(5): 10-15(in Chinese).

[11] Zhu, S.L. 2004. Development and Energy Demand of Private Vehicle in Beijing. Energy of China 26(9): 2833(in Chinese). 